\title{
Synthesis of hydrophobic nanostructured zinc borate from zinc carbonate, and characterization of the product
}

\author{
Nurcan Tugrul $\cdot$ Melek Bardakci $\cdot$ Emre Ozturk
}

Received: 27 August 2013/Accepted: 12 January 2014/Published online: 1 February 2014

(C) The Author(s) 2014. This article is published with open access at Springerlink.com

\begin{abstract}
In general, zinc oxide and boric acid are used to produce zinc borate. In this study, zinc carbonate was used instead of zinc oxide as the novel zinc source. The purpose of this study was to synthesize hydrophobic, nanostructured zinc borate $\left(3 \mathrm{ZnO} \cdot 3 \mathrm{~B}_{2} \mathrm{O}_{3} \cdot 3.5 \mathrm{H}_{2} \mathrm{O}\right)$ by reaction of zinc carbonate, instead of zinc oxide, with boric acid reference material, and with zinc borate reference material as seed. The modifying agents propylene glycol, kerosene, and oleic acid were used to produce hydrophobic zinc borate. Different solvents (isopropyl alcohol, ethanol, and methanol) were used to obtain a homogeneous phase. The effects of different modifying agents and solvents on the hydrophobicity and nanostructure of the product were investigated. The synthesized zinc borate was characterized by X-ray diffraction and Fourier-transform infrared spectroscopy. Contact angles were measured to determine the hydrophobicity of the products and scanning electron microscopy was used to study both the morphology and nanostructure of the products. Hydrophobic, nanostructured zinc borate was successfully produced by use of zinc carbonate instead of zinc oxide as the novel zinc source. Use of different modifying agents and solvents affected both hydrophobicity and nanostructure.
\end{abstract}

Keywords Hydrophobicity $\cdot$ Nanostructure $\cdot$ Zinc borate $\cdot$ Zinc carbonate

\section{Introduction}

Zinc borate is a flame-retardant additive used in polymer, wood, and textile products. There are different types of zinc borate with different chemical compositions and

\footnotetext{
N. Tugrul $(\bowtie) \cdot$ M. Bardakci · E. Ozturk

Department of Chemical Engineering, Y1ld1z Technical University, Davutpasa St., N.127, Esenler, Istanbul, Turkey

e-mail: ntugrul@hotmail.com; ntugrul@yildiz.edu.tr
} 
structures, one of these is crystalline zinc borate with the formula $2 \mathrm{ZnO} \cdot 3 \mathrm{~B}_{2} \mathrm{O}_{3} \cdot 3.5 \mathrm{H}_{2} \mathrm{O}$. This form of zinc borate is usually produced by reaction of zinc oxide and boric acid under appropriate temperature and mixing conditions.

Gürhan et al. [5] produced small zinc borate particles by optimizing the experimental conditions. Tian et al. [8] synthesized hydrophobic $\mathrm{Zn}_{2} \mathrm{~B}_{6} \mathrm{O}_{11} \cdot 3 \mathrm{H}_{2} \mathrm{O}$ nanoplatelets from $\mathrm{Na}_{2} \mathrm{~B}_{4} \mathrm{O}_{7} \cdot 10 \mathrm{H}_{2} \mathrm{O}$ and $\mathrm{ZnSO}_{4} \cdot 7 \mathrm{H}_{2} \mathrm{O}$ as raw materials by use of a one-step precipitation reaction with a modifying agent. Zheng et al. [10] synthesized zinc borate $\left(4 \mathrm{ZnO} \cdot \mathrm{B}_{2} \mathrm{O}_{3} \cdot \mathrm{H}_{2} \mathrm{O}\right)$ nanowhiskers by use of a one-step precipitation reaction in an aqueous solution of sodium borate $\left(\mathrm{Na}_{2} \mathrm{~B}_{4} \mathrm{O}_{7} \cdot 10 \mathrm{H}_{2} \mathrm{O}\right)$ and zinc nitrate $\left(\mathrm{Zn}\left(\mathrm{NO}_{3}\right)_{2} \cdot 6 \mathrm{H}_{2} \mathrm{O}\right)$ with a phosphate ester as modifying agent. Li et al. [6] synthesized hydrophobic zinc borate $\left(2 \mathrm{ZnO} \cdot 3 \mathrm{~B}_{2} \mathrm{O}_{3} \cdot 3.5 \mathrm{H}_{2} \mathrm{O}\right)$ nanoflakes by solid-liquid reaction of zinc oxide $(\mathrm{ZnO})$ and boric acid $\left(\mathrm{H}_{3} \mathrm{BO}_{3}\right)$ in the presence of oleic acid. To increase the flame-retardant properties of polyurethane (PU), Gao et al. [3] prepared PU/zinc borate (PU/ZB) nanocomposites by in-situ polymerization. Gao et al. [4] reported the structure and morphology of zinc borates $\left(2 \mathrm{ZnO} \cdot 3 \mathrm{~B}_{2} \mathrm{O}_{3} \cdot 3 \mathrm{H}_{2} \mathrm{O}\right.$ and $\left.2 \mathrm{ZnO} \cdot 3 \mathrm{~B}_{2} \mathrm{O}_{3} \cdot 7 \mathrm{H}_{2} \mathrm{O}\right)$ prepared from zinc sulfate hydroxide and boric acid, with sodium dodecyl benzene sulfonate, poly(ethylene glycol), and citric acid as organic modifiers. Bardakci et al. [2] prepared zinc borate by reaction of zinc oxide and boric acid in the absence or presence of the surfactant cumene-terminated poly(styrene-co-maleic anhydride), PSMA, added to the reaction medium at different concentrations $(0.1-1 \mathrm{wt} \%$ of water) to investigate its effect on the growth and agglomeration of the particles during the reaction. Acarali et al. [1] synthesized zinc borate from zinc oxide and boric acid reference material, with zinc borate reference material as seed, and investigated the effects of modifying agents and reaction conditions on hydrophobicity and yield.

Previous work on the synthesis of zinc borate has included reaction of zinc salts and borate salts in hot water $\left(\geq 60{ }^{\circ} \mathrm{C}\right)$, use of the ethanol supercritical fluid drying technique, and reaction of zinc oxide and boric acid [2, 7-9]. In this study, in contrast with previous studies, zinc borate was synthesized from zinc carbonate, as novel zinc source, with boric acid reference material, and with zinc borate reference material as seed. Because the zinc borate reference material used was hydrophilic, modifying agents were required to produce hydrophobic, nanostructured zinc borate. The effects of different modifying agents (propylene glycol, kerosene, and oleic acid) and different solvents (isopropyl alcohol, ethanol, and methanol) on hydrophobicity and nanostructure were therefore investigated. Hydrophobicity was increased by use of modifying agents and different solvents. The zinc borate produced was characterized by X-ray diffraction (XRD) and Fourier-transform infrared (FTIR) spectroscopy. Scanning electron microscopy (SEM) was used to study the morphology and nanostructure of the products. Contact angles were measured to determine hydrophobicity. In conclusion, hydrophobic, nanostructured zinc borate was successfully synthesized from zinc carbonate instead of zinc oxide as zinc source. The procedure reported here is, therefore, a new method for synthesis of hydrophobic, nanostructured zinc borate. The hydrophobicity and nanostructure of the product can be modified by use of different modifying agents and solvents. 


\section{Experimental}

\section{Materials}

Boric acid reference material (molecular formula: $\mathrm{B}(\mathrm{OH})_{3}, 99.9 \%$ pure) and zinc borate reference material were obtained from Eti Mine Works. Zinc carbonate (Kadim Chemistry, 96-97 \% pure) was obtained from Colakoglu Chemicals. Propylene glycol was obtained from Solventas. Kerosene, oleic acid, and solvents were supplied by Prolab.

\section{Methods}

Zinc borate was synthesized by the reaction of zinc carbonate, boric acid reference material, and zinc borate reference material, with propylene glycol, kerosene or oleic acid as modifying agents, in a variety of solvents (isopropyl alcohol, ethanol, or methanol), used to obtain a homogeneous phase. Zinc borate reference material was used as a seed crystal to improve the quality of the product. The reaction was conducted in a closed glass beaker at $95{ }^{\circ} \mathrm{C}$. Temperature was controlled by use of a digital temperature sensor and magnetic stirrer hot-plate; the reaction was stirred continuously (Fig. 1). The products were dried at $105{ }^{\circ} \mathrm{C}$ for $20 \mathrm{~h}$. Dry, finely powdered zinc borate particles were obtained.

\section{Characterization}

All products were characterized by XRD (Philips Panalytical, Xpert-Pro). FTIR (Perkin Elmer, Spectrum one) was used to identify the functional groups present in the products. To determine hydrophobicity, contact angle was measured by use of a Cam 200. The morphology and nanostructure of the products were studied by SEM (Apollo 300; Cam Scan). The results were indicative of successful synthesis of hydrophobic, nanostructured zinc borate.

\section{Results and discussion}

X-ray diffraction patterns of zinc borates

In XRD analysis peaks from the synthesized hydrophobic zinc borate were similar to those from zinc borate reference material. The characteristic XRD peaks of zinc borate were observed in the range $15-70^{\circ} 2 \theta$, as expected (Fig. 2). All diffraction peaks were similar to those of $3 \mathrm{ZnO} \cdot 3 \mathrm{~B}_{2} \mathrm{O}_{3} \cdot 3.5 \mathrm{H}_{2} \mathrm{O}$ (JCPDS File No. 35-0433).

FTIR spectra of zinc borates

FTIR analysis was performed with a Perkin-Elmer Spectrum One instrument. The band which indicates stretching vibrations of $\mathrm{O}-\mathrm{H}$ is clearly seen between 2,500 and $3,500 \mathrm{~cm}^{-1}$. Weak bending vibrations of $\mathrm{H}-\mathrm{O}-\mathrm{H}$ bonds ascribed to water of 

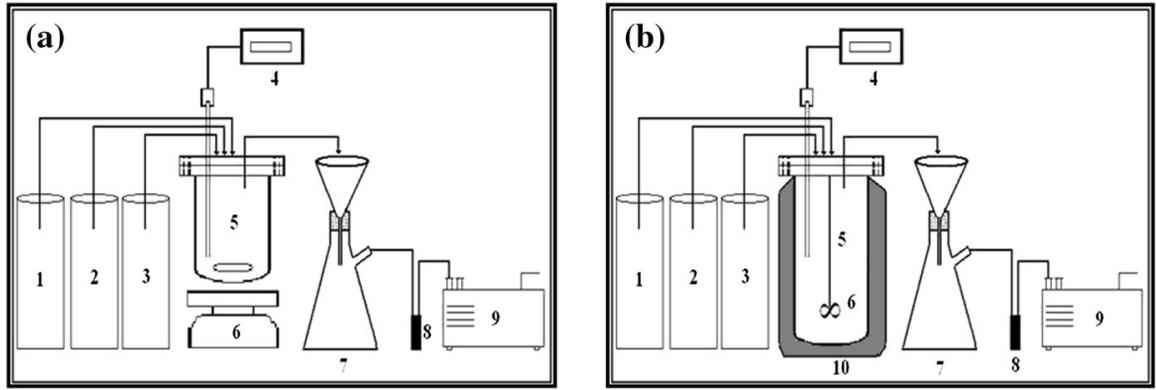

Fig. 1 Experimental set up: a, magnetically stirred system; b, mechanically stirred system; 1 , boric acid reference material; 2 , zinc oxide; 3 , zinc borate reference material; 4 , digital temperature controller; 5 in a, glass beaker; 5 in b, reactor; 6 in a, magnetic stirrer hotplate; 6 in $\mathbf{b}$, mechanical stirrer; 7 , solid-liquid phase separation apparatus; 8 , trap; 9 , vacuum pump; 10, heating jacket

Table 1 Chemical composition of zinc borate reference material and zinc borate synthesized under different reaction conditions

\begin{tabular}{lllllll}
\hline Run no & $\begin{array}{l}\mathrm{ZnO} \\
(\%)\end{array}$ & $\begin{array}{l}\mathrm{B}_{2} \mathrm{O}_{3} \\
(\%)\end{array}$ & $\begin{array}{l}\mathrm{H}_{2} \mathrm{O} \\
(\%)\end{array}$ & $\begin{array}{l}\text { Modifying } \\
\text { agent }\end{array}$ & Solvent & Formula \\
\hline $\begin{array}{l}\text { ZB reference } \\
\text { material }\end{array}$ & 39.21 & 47.46 & 13.33 & - & - & $2.1 \mathrm{ZnO}^{2} \cdot 3 \mathrm{~B}_{2} \mathrm{O}_{3} \cdot 3.2 \mathrm{H}_{2} \mathrm{O}$ \\
$\begin{array}{l}\text { ZB-1 } \\
\text { ZB-2 }\end{array}$ & 34.71 & 47.25 & 18.04 & $\begin{array}{l}\text { Propylene } \\
\text { glycol }\end{array}$ & Ethanol & $2.0 \mathrm{ZnO}^{2} \cdot 3 \mathrm{~B}_{2} \mathrm{O}_{3} \cdot 4.4 \mathrm{H}_{2} \mathrm{O}$ \\
ZB-3 & 26.97 & 47.38 & 25.65 & $\begin{array}{c}\text { Kerosene } \\
\text { Oleic acid }\end{array}$ & $\begin{array}{l}\text { Methanol } \\
\text { IPA }\end{array}$ & $\begin{array}{l}1.5 \mathrm{ZnO}^{2} \cdot 3 \mathrm{~B}_{2} \mathrm{O}_{3} \cdot 6.3 \mathrm{H}_{2} \mathrm{O} \\
1.9 \mathrm{ZnO}_{3} \cdot 3 \mathrm{~B}_{2} \mathrm{O}_{3} \cdot 5.8 \mathrm{H}_{2} \mathrm{O}\end{array}$ \\
\hline
\end{tabular}

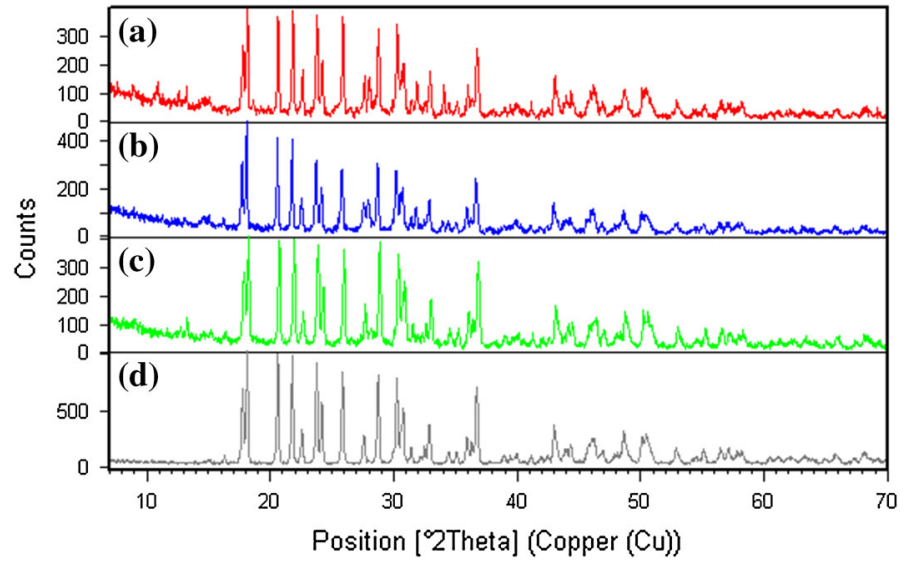

Fig. 2 XRD diffraction patterns: a hydrophobic zinc borate modified by use of propylene glycol, b hydrophobic zinc borate modified by use of kerosene, $\mathbf{c}$ hydrophobic zinc borate modified by use of oleic acid, $\mathbf{d}$ zinc borate reference material 


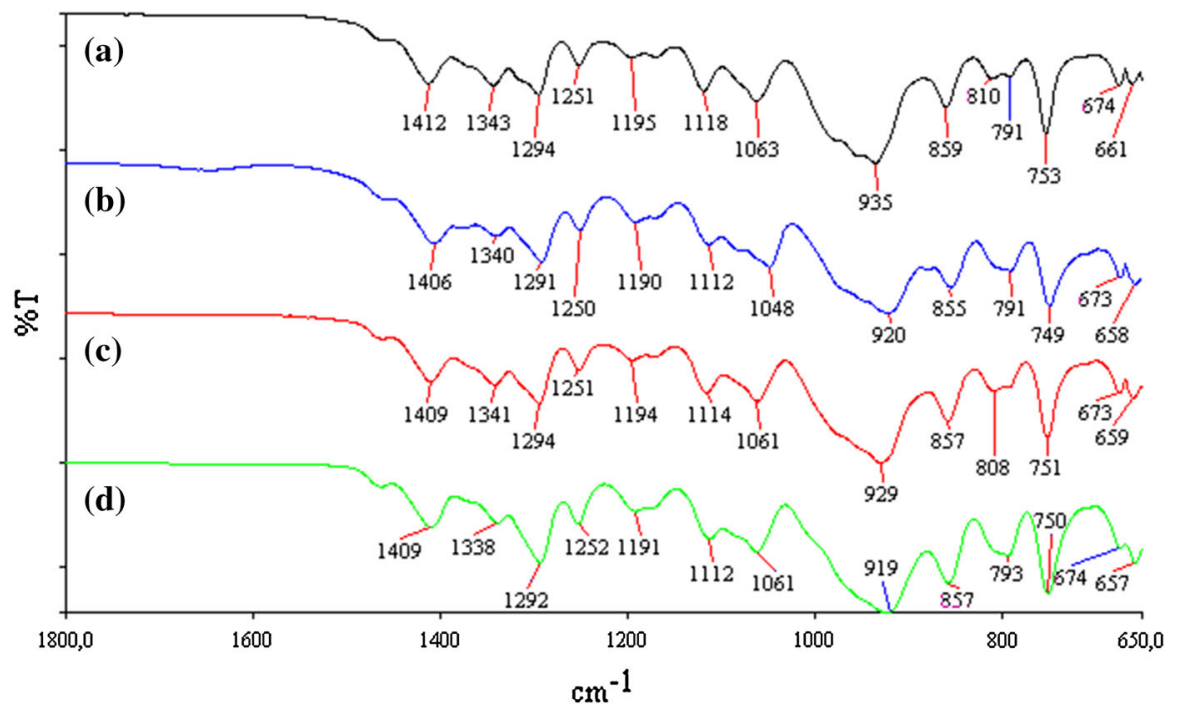

Fig. 3 FTIR spectra of: a hydrophobic zinc borate modified by use of propylene glycol, b hydrophobic zinc borate modified by use of kerosene, $\mathbf{c}$ hydrophobic zinc borate modified by use of oleic acid, $\mathbf{d}$ zinc borate reference material

crystallization present in the compound can be seen between 1,600 and 1,700 $\mathrm{cm}^{-1}$. The band between 1,300 and $1,450 \mathrm{~cm}^{-1}$ is assigned to asymmetric stretching vibrations of trihedral $\left(\mathrm{BO}_{3}\right)$ borate groups. The peaks in the range 1,000-1,150 and $700-900 \mathrm{~cm}^{-1}$ are assigned to asymmetric and symmetric stretching vibrations of tetrahedral $\left(\mathrm{BO}_{4}\right)$ borate groups. The peak between 650 and $750 \mathrm{~cm}^{-1}$ is ascribed to in-plane bending vibrations of trihedral $\left(\mathrm{BO}_{3}\right)$ groups. Therefore, use of different modifying agents, solvents, and the stirred system did not affect the structure, which was similar to that of zinc borate reference material, as in previous studies $[1,2,9]$. The FTIR spectra of the products are indicative of formation of zinc borate (Fig. 3).

Water contact angle of zinc borates

Water drop contact angle, a measure of surface wetting, is widely used for evaluation of surface hydrophobicity. A wettable or hydrophilic surface will have a contact angle $<90^{\circ}$. To study its surface characteristics, contact angle was measured for the synthesized zinc borate powder [1,8]. The contact angle of pure hydrophilic zinc borate powder was very small. Use of modifying agents and different solvents resulted in a shift from hydrophilic to hydrophobic compared with zinc borate reference material. The contact angle was $21.66^{\circ}$ when propylene glycol was used as modifying agent and $17.95^{\circ}$ when kerosene was used. When oleic acid was used the contact angle was $103.19^{\circ}$. In conclusion, it was seen that changing the modifying agent affected the hydrophobicity of zinc borate (Fig. 4), and use of oleic acid as modifying agent resulted a shift from hydrophilic to hydrophobic . 

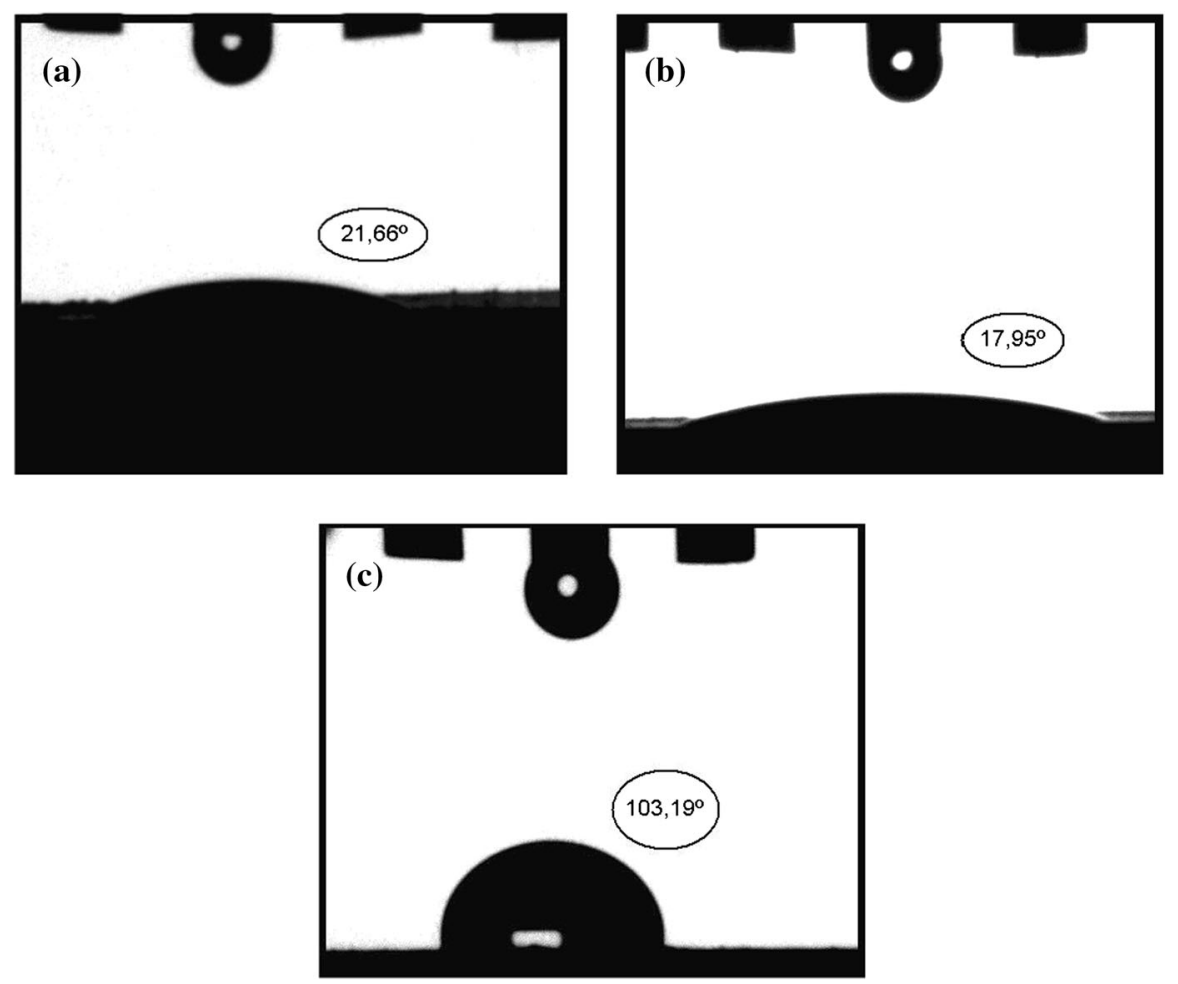

Fig. 4 Contact angles of zinc borate modified by use of: a propylene glycol, b kerosene, c oleic acid

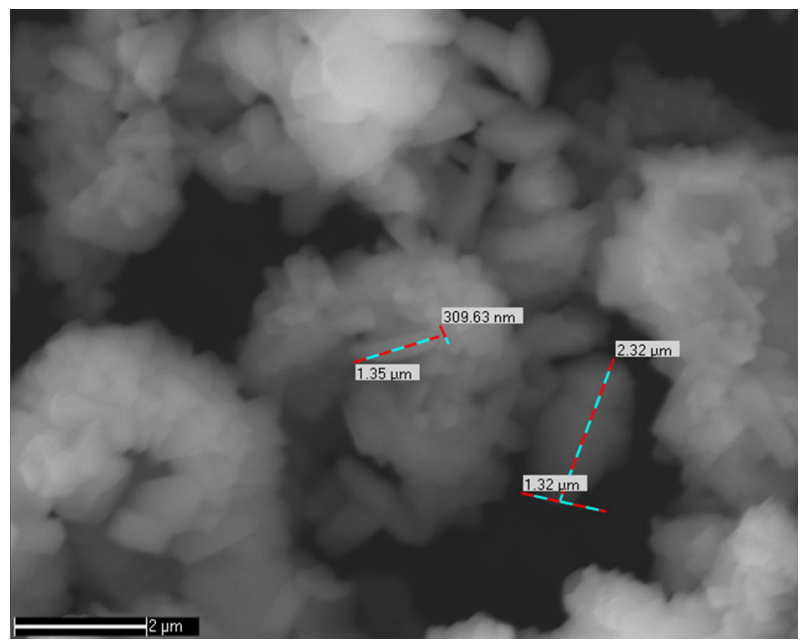

Fig. 5 SEM image of zinc borate reference material 


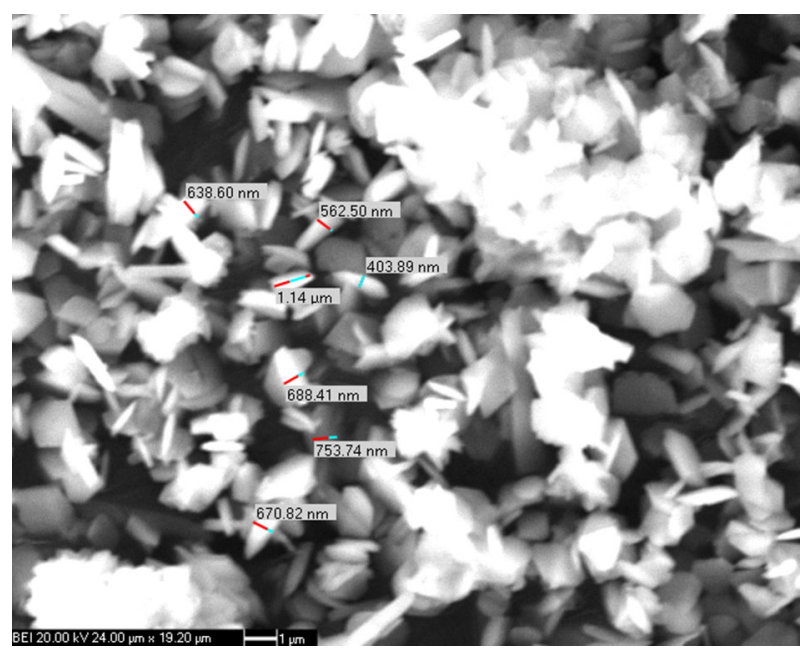

Fig. 6 SEM image of hydrophobic zinc borate modified by propylene glycol

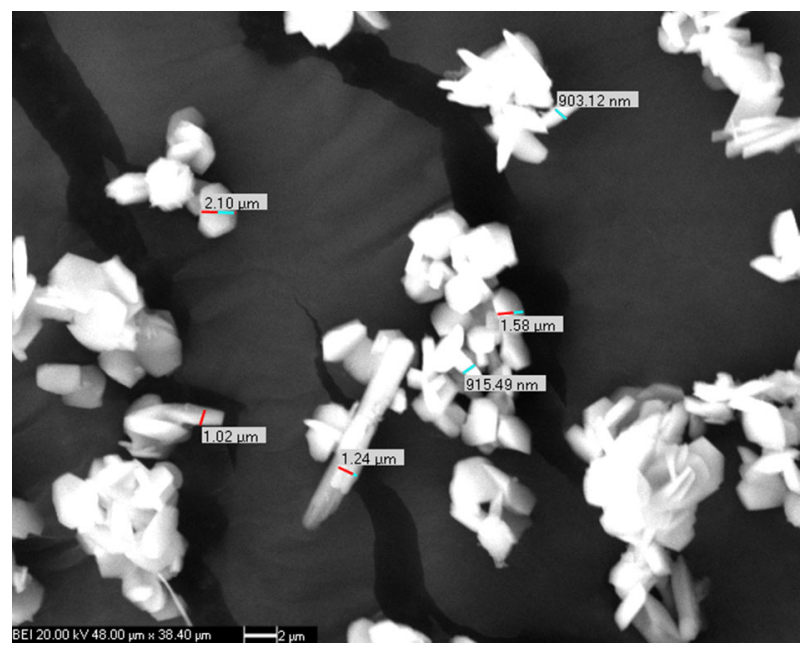

Fig. 7 SEM image of hydrophobic zinc borate modified by kerosene

SEM micrographs of the zinc borates

SEM was used to study the morphology of the products. Figure 5 shows the SEM image of zinc borate reference material. Particle size ranged between $309.63 \mathrm{~nm}$ and $2.32 \mu \mathrm{m}$. Figure 6 shows the SEM image of hydrophobic zinc borate produced from zinc borate reference material and zinc carbonate, with propylene glycol as modifier, in ethanol. Particle size ranged between $403.89 \mathrm{~nm}$ and $1.14 \mu \mathrm{m}$. Figure 7 shows the SEM image of hydrophobic zinc borate produced from zinc borate reference material and zinc carbonate, with kerosene as modifier, in methanol. Particle size ranged 


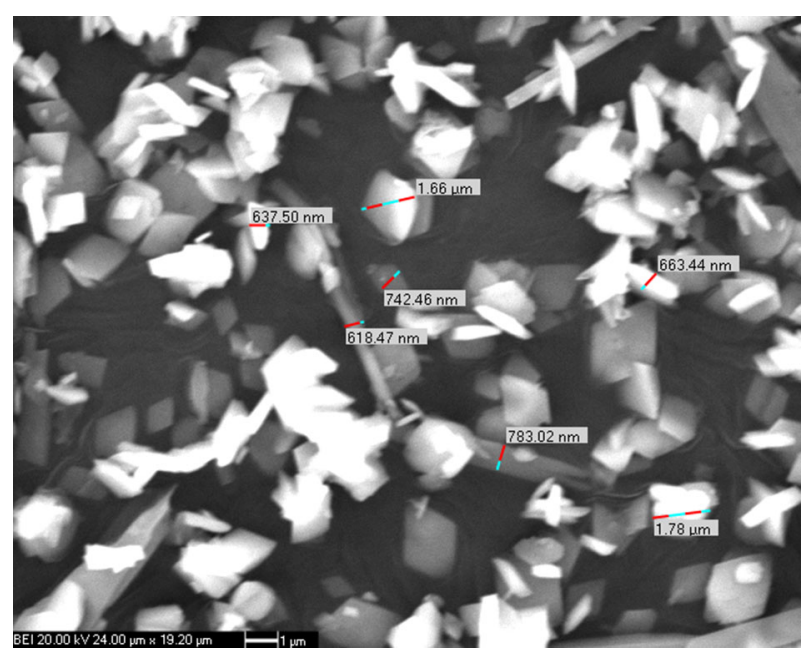

Fig. 8 SEM image of hydrophobic zinc borate modified by oleic acid

between $903.12 \mathrm{~nm}$ and $2.10 \mu \mathrm{m}$. Figure 8 shows the SEM image of hydrophobic zinc borate produced from zinc borate reference material and zinc carbonate, with oleic acid as modifier, in isopropyl alcohol. Particle size ranged between $618.47 \mathrm{~nm}$ and $1.78 \mu \mathrm{m}$. As is apparent from Figs. 5, 6, 7 and 8, use of propylene glycol with ethanol, kerosene with methanol, and oleic acid with isopropyl alcohol affected the morphology of zinc borate. Nanostructured zinc borate was produced by use of zinc borate reference material and zinc carbonate with propylene glycol, kerosene, or oleic acid as modifier in ethanol, methanol, or isopropyl alcohol.

\section{Conclusions}

The results from this analysis showed that hydrophobic nanostructured zinc borate $\left(3 \mathrm{ZnO} \cdot 3 \mathrm{~B}_{2} \mathrm{O}_{3} \cdot 3.5 \mathrm{H}_{2} \mathrm{O}\right)$ was successfully synthesized by reaction of zinc carbonate, as novel zinc source, with boric acid reference material, and zinc borate reference material as the seed. The synthesized zinc borate was characterized by XRD and FTIR. The results showed that synthesis of hydrophobic nanostructured zinc borate was achieved. The zinc borate reference material used was hydrophilic, and modifying agents (propylene glycol, kerosene, and oleic acid) and different solvents (isopropyl alcohol, ethanol, and methanol) were required for preparation of hydrophobic nanostructured zinc borate. The contact angle of zinc borate reference material was $0^{\circ}$, which means the zinc borate reference material had a hydrophilic structure. There was shift from hydrophilic properties to hydrophobic properties when modifying agents and solvents were used. The contact angle was $21.66^{\circ}$ when propylene glycol was used, $17.95^{\circ}$ when kerosene was used, and $103.19^{\circ}$ when oleic acid was used. Thus use of a modifying agent with solvent affected the hydrophobicity. SEM was used to study the morphology and nanostructure of the products. SEM images showed the minimum 
particle size of zinc borate reference material was $309.63 \mathrm{~nm}$. The particle size of hydrophobic zinc borate produced from zinc borate reference material and zinc carbonate, with propylene glycol as modifier and ethanol as solvent, was $403.89 \mathrm{~nm}$. The particle size of hydrophobic zinc borate produced from zinc borate reference material and zinc carbonate, with kerosene as modifier and methanol as solvent was $903.12 \mathrm{~nm}$. The particle size of hydrophobic zinc borate produced from zinc borate reference material and zinc carbonate, with oleic acid as modifier and isopropyl alcohol as solvent was $618.47 \mathrm{~nm}$. Use of different modifying agents did not affect the structure, and homogeneous nanostructured zinc borate was obtained from zinc borate reference material and zinc carbonate, with propylene glycol, kerosene, or oleic acid as modifier, and with ethanol, methanol, or isopropyl alcohol as solvent.

Open Access This article is distributed under the terms of the Creative Commons Attribution License which permits any use, distribution, and reproduction in any medium, provided the original author(s) and the source are credited.

\section{References}

1. Baran Acarali, N. Tugrul, E. Moroydor Derun, S. Piskin, Production and characterization of hydrophobic zinc borate by using palm oil. Int. J. Miner Metall. Mater. 20(11), 1081-1088 (2013)

2. M. Bardakcı, N. Baran Acaralı, N. Tugrul, E. Moroydor Derun, M.B. Pıskın, Production of zinc borate for pilot-scale equipment and effects of reaction conditions on yield. Mater. Sc1. (Medžıgotyra) 19:2, 158-163 (2013)

3. X. Gao, Y. Guo, Y. Tian, S. Li, S. Zhou, Z. Wang, Synthesis and characterization of polyurethane/ zinc borate nanocomposites. Colloids Surf. A 384, 2-8 (2011)

4. J. Gao, H. Yin, A. Wang, T. Jiang, Preparation of zinc borates with different structures and morphologies and their effect on thermal and oxidative stability of polyvinyl alcohol. Powder Technol. 237, 537-542 (2013)

5. D. Gürhan, G.Ö. Çakal, İ. Eroğlu, S. Özkar, Improved synthesis of fine zinc borate particles using seed crystals. J. Cryst. Growth 311, 1545-1552 (2009)

6. S. Li, B. Long, Z. Wang, Y. Tian, Y. Zheng, Q. Zhang, Synthesis of hydrophobic zinc borate nanoflakes and its effect on flame retardant properties of polyethylene. J. Solid State Chem. 183, 957-962 (2010)

7. Y. Tian, Y. Guo, M. Jiang, Y. Sheng, B. Hari, G. Zhang, Y. Jiang, B. Zhou, Y. Zhu, Z. Wang, Synthesis of hydrophobic zinc borate nanodiscs for lubrication. Mater. Lett. 60, 2511-2515 (2006)

8. Y. Tian, Y. He, L. Yu, Y. Deng, Y. Zheng, F. Sun, Z. Liu, Z. Wang, In situ and one-step synthesis of hydrophobic zinc borate nanoplatelets. Colloids Surf. 312, 99-103 (2008)

9. C. Ting, D. Jian-Cheng, W. Long-Shuo, F. Gang, Preparation and characterization of nano-zinc borate by a new method. J. Mater. Process. Technol. 209, 4076-4079 (2009)

10. Y. Zheng, Y. Tian, H. Ma, Y. Qu, Z. Wang, D. An, S. Guan, X. Gao, Synthesis and performance study of zinc borate nanowhiskers. Colloids Surf. A 339, 178-184 (2009) 